\title{
An Integrated Valuation Tool for Uncertainties in Mining
}

\author{
Claudel M Tsafack, Bernd G Lottermoser \\ Institute of Mineral Resources Engineering, RWTH Aachen University \\ Wüllnerstrasse 2, 52062 Aachen, Germany \\ tsafack@mre.rwth-aachen.de; lottermoser@mre.rwth-aachen.de
}

\section{Extended Abstract}

Worldwide mining operations are as much as $28 \%$ less productive today than a decade ago [1] [2]. The way forward to address the industry's productivity challenge is to embed effective management operating systems at mines, to prioritize operational excellence and capabilities development, and to focus on innovation [1] [2]. It also requires a determined focus on eliminating all forms of waste, reducing variability, and improving productivity of assets through advanced reliability and maintenance approaches, together with increased flexibility about changing conditions. However, the merit of incorporating greater flexibility needs to be evaluated to determine the true value added.

The aim of this study is to establish an integrated valuation tool that allows a deterministic evaluation of different mining scenarios and an assessment of flexibility options in mining. The tool is to allow an evaluation of possible mining production activities (e.g. extraction, transport), which, if implemented, would lead to uncertain processes and outcomes. The importance of a holistic evaluation of changed mining practices is highlighted by the fact that optimizing a single production activity (e.g. extraction, transport) may potentially impact on associated or downstream processes, which may either have a positive or a negative effect on the productivity of a mining operation. Common evaluation tools of mining projects assume that the variables used to establish the economic value of a mineral resource are fixed and known. This assumption, however, ignores possible changes in practices and engineering design that may occur during the project life time and add value to the project. By doing so, the potential value embedded in applying flexibility options is ignored.

Today, incorporating flexibility in project valuation processes and determining their value with regard to uncertain processes is possible through the use of innovative evaluation tools. The Real Option Valuation Theory (ROV) was introduced for the first time by Brennan and Schwartz [3] to evaluate natural resource projects. However, more recent studies apply Real Option "In" Project (ROIP), with the distinctive feature of assessment and evaluation based on project internal variables and technical systems. In this study, a series of components are used to consider uncertainties, flexibility and options. Binomial Lattices are used as an option pricing model or for conducting evaluations. In conclusion, implementing flexibility within uncertain processes enhances productivity. The ROIP technique also allows mitigation of risks. Thus, integrated valuation tools are extremely valuable instruments for the assessment of mining operations. For instance preliminary results of the valuation of a "non-variable ore quality throughput" option to the Mill shows an improvement of $10 \%$ of the initial NPV of a considered hypothetical copper project.

\section{References}

[1] Deloitte. (2015, March 23). Tracking the trends 2015. The top 10 issues mining companies will face this year. [Online]. Available: http://www2.deloitte.com/content/dam/Deloitte/fpc/Documents/secteurs/energie-etressources/deloitte_etude-tracking-the-trends-2015-en.pdf.

[2] McKinsey. (2015, May 12). Productivity in mining operations: reversing the downward trend. [Online]. Available: http://www.mckinsey.com/industries/metals-and-mining/our-insights/productivity-in-mining-operations-reversingthe-downward-trend.

[3] M. Brennan and E. Schwartz, "Evaluating natural resource investments," J. Business, vol. 58, no. 2, pp. 135 - 157, 1985 . 